\title{
Using consensus methods to establish multidisciplinary perspectives on research priorities for primary care
}

Catherine Evans, Stephen Rogers and Caroline McGraw Department of Primary Care and Population Sciences, RFUCL Medical School, UK and Greg Battle, Lee Furniss North Islington Primary Care Group, UK

\begin{abstract}
The execution and incorporation of research into practice is influenced by the relevance and credibility of the work undertaken. Part of this process can be to identify priority research questions from the service provider perspective. We sought to obtain a multidisciplinary consensus on priority research questions around the broad issue of prescribing in an inner London Primary Care Group locality. Participants were drawn from general practice, primary care nursing and community pharmacy. This paper explores how two formal consensus methods were used to facilitate multidisciplinary participation within the research arena, and the extent to which a convergence of opinion between professional groups was obtained. The use of a structured nominal group interview technique abated professional dominance and generated a diverse array of research questions. An iterative Delphi process secured a wide consensus of opinion regarding the relevance of these questions to practice. The richness of the research questions generated was attributed to the consultation process and the ability of the consensus methods used to capture the multidisciplinary perspective. The practice based research questions identified were diverse and suited to a collaborative research approach.
\end{abstract}

Key words: consensus methods; multidisciplinary; prescribing

\section{Background}

The organization of primary care is complex, with local and regional differences, and historic and political factors having an important influence. Although there is increasing integration between different groups, general practice, pharmacy services and community nursing services remain largely distinct, with their own priorities, schedules and accountability frameworks. The theme of partnership and integration in healthcare is now high on the political agenda and much work is underway to improve communication and joint working between service providers (Department of Health, 1997a; 1997b; Poxton, 1999).

Research in primary care has gained a high

Address for correspondence: Catherine Evans, Research Fellow, Primary Care Nursing Research Unit, Rm G15, King's College London, James Clerk Maxwell Building, 57 Waterloo Road, London SE1 8WA, UK. Email: catherine.j.evans@kcl.ac.uk profile in recent years. Not only has there been recognition of the importance of a research base for primary care but also the need to involve service providers in the research process to ensure the implementation of findings into practice. Shared concerns are recognized through joint working and there is a growing realisation that many questions cannot be satisfactorily addressed by a uni-professional approach. This implies the need for multidisciplinary collaboration not only in service delivery but also in the identification of research priorities (Department of Health, 1997b; Elwyn and Smail, 1999; Poxton, 1999).

The London Region Research and Development Programme launched the Primary Care Research Incentives Programme in February 2000 to engage local primary care practitioners in studies of a collaborative nature. North Islington Primary Care Group (PCG) was funded to identify research priorities around the broad issue of prescribing within its locality. This was carried out in a 
Definition of the problem

What are the priority research questions on the effectiveness, cost and quality of prescribing in this locality?

\section{STAGE 1}

Purposive sample of primary health care professionals $(n=12)$

\section{$\downarrow$}

The Group Interview

\section{STAGE 2}

\section{First round of Delphi}

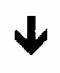

Second round of Delphi

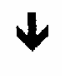

Review of the literature to relevant to research questions
4 GPs (2 single handed)

2 Practice Nurses, 2 District Nurses and 4 Pharmacists

$\rightarrow$ Nominal group consensus interview to develop initial list of priority research areas/questions 
multidisciplinary perspectives on research priorities in primary care.

\section{Methods}

\section{The setting}

North Islington PCG covers an area of north London inhabited by 140000 people. Historically, the area has an underdeveloped primary care sector and is currently served by 31 practices, 18 of which are single handed, and a large community trust. None of the general practices dispense medication and patients are served by one of 23 community pharmacies. The consultation exercise aimed to draw on the opinion of three professional groups, general practitioners (GPs), primary care nurses and community pharmacists. By recruiting from within one PCG, it was anticipated that the final research questions would have direct relevance to the PCG, local service providers and users.

\section{The process}

A two-stage design was used to identify practitioners' priority research questions on the effectiveness, cost and quality of prescribing. In stage 1 , a multidisciplinary nominal group interview technique (NGT) was employed to generate research questions. In stage 2, a two round Delphi survey was used to obtain a wider consensus from service providers across the PCG. A literature review was conducted to provide background material relevant to the questions identified. Figure 1 provides an overview of the study design.

\section{Stage 1: The nominal group technique interview}

We sought a nonrandom convenience sample of 12 informants (all with a self identified interest in prescribing) from the local PCG to participate in a nominal group interview. Four representatives were drawn from each of the three disciplines of general practice, primary care nursing and community pharmacy. A one-hour nominal group interview was organized at a central location within the PCG. A NGT five stage structured format (Van de Ven and Delbecq, 1972) was used (Figure 2).

In keeping with the NGT literature, a single question was used to gather data:

What research questions on the effectiveness, cost and quality of prescribing should be

\section{The five stage NGT format}

1. Silent generation of ideas in writing.

2. Round robin to record individual ideas on flip paper.

3. Clarification and amalgamation of ideas in a group discussion.

4. Individual voting and ranking to identify the priority areas.

5. Group discussion of the priority ideas identified in the interview.

Figure 2 Structure of the NGT interview

given priority for support as research questions in this locality?

In response to the question, participants were encouraged to write down all ideas (stage 1), both specific and broad, which they subsequently presented one by one, in a series of rounds (stage 2). Ideas were recorded on a flip chart, and then clarified in open discussion; linked ideas were amalgamated and numbered (stage 3). Participants were then given five cards each on which to first write the number of the idea and then rank it; the most important receiving the highest score of five through to the least with a score of one (stage 4). The scores were then recorded on overhead acetate and the voting pattern discussed (stage 5). Participants were asked to consider both the number of votes awarded to each idea as well as the consolidated scores. This was intended to prevent the obscuring of different voting patterns, for example, of one idea receiving multiple votes but of a low rank being obscured by an idea receiving a single high rank (Moore, 1987).

\section{Stage 2: The two round Delphi Questionnaire}

In order to ensure a balanced representation of pharmacists, GPs (single handed and group practice) and nurses (district nurses and practice nurses) a stratified random sampling technique was used. The sampling frame comprised 28 pharma- 
cists, 100 GPs (20 single-handed), and 56 nurses (15 district nurses and 41 practice nurses).

A postal questionnaire was designed for the two round Delphi survey from the outputs of the NGT interview. In the first round, the questionnaire detailed the six priority research areas, identified during Stage 1, in the form of research questions. Questionnaires were sent to all pharmacists $(\mathrm{n}=$ 28 ) and district nurses $(n=15)$, and to a random sample of practice nurses $(\mathrm{n}=15)$, single-handed GPs $(\mathrm{n}=15)$ and GPs in group practice $(\mathrm{n}=15)$ (total, $\mathrm{n}=88$ ). In the first round Delphi respondents were asked to score each of the six research questions on a Likert scale from zero (low priority) to nine (high priority). The questionnaire, and a covering letter, was sent with a prepaid envelope. Follow up telephone calls were made to nonresponders after ten days.

Responses were entered onto an SPSS database (Release 7.5.1, Chicago Illinois) and descriptive statistics were generated for each statement. Analysis focused on measures of central tendency for the Likert scale scores as a whole and by professional grouping. In the second round Delphi, the questionnaire used the same research question and Likert scale format, but the mean scores from the first round were indicated on each measurement scale. Respondents were asked to score the questions once more, reflecting on their score in light of their colleague's earlier responses. Second round questionnaires were circulated with a new covering letter and prepaid envelope. Once more, nonresponders were telephoned after ten days. The method of data analysis from the first round was replicated. The final activity was a half-day workshop open to all practitioners participating in the consensus processes. Following instruction on literature searching techniques, participants were helped compile a summary of published work on the highest-ranking research questions.

\section{Results}

\section{Stage 1: The Nominal Group Interview}

Ten people attended the NGT interview (three GPs, three community pharmacists, two practice nurses and two district nurses). Initially, participants identified 30 priority research areas. The number of priority research areas was reduced to 16 during the clarification and amalgamation of ideas stage of the interview. Aggregation of the ranks awarded to each question and analysis of their central tendency revealed the groups six priority research themes (Table 1).

The results of the group interview (which included the flip chart data) were reviewed by the steering group and the six priority themes developed to form coherent research questions (see Table 3) for presentation in the Delphi Questionnaire.

\section{Stage 2: The Delphi Questionnaire}

The response rate in the first round Delphi was 53 percent $(n=47)$ and 38 percent $(n=34)$ in the second. Table 2 summarizes responses to the two round Delphi by professional grouping.

The mean was used to calculate the measure of central tendency for each question. This produced more sensitive values than the application of the median and aided the comparison of scores for the different questions. Table 3 displays the priority position Delphi respondents awarded to each of the six research questions.

In the case of the first four questions listed in Table 3, overall rankings did not change between the first and second rounds. In the first five, professional groups tended to score consistently between one round and the next (all groups reduced their score in the second round for the question on addressing information needs around hormone replacement therapy (HRT)). Scores were similar across professional groups except for the question on community pharmacist intervention to improve GP prescribing (lower score awarded by GPs) and the question on addressing information needs around HRT (higher score awarded by nurses).

\section{Discussion}

This paper describes a multidisciplinary research priority setting exercise, focusing on cost and quality issues around prescribing in an inner London PCG. Rather than seeking the views of experts, the views of health professionals were sought by using adapted forms of traditional consensus methods. Service providers are in a good position to identify priority areas for research and development, and it has been suggested that their involvement in the research process might facilitate the implementation of research into practice (Elwyn 
Table 1 Research areas identified in the NGT interview

\begin{tabular}{|c|c|c|c|}
\hline Priority research areas/questions & $\begin{array}{l}\text { Number } \\
\text { of votes }\end{array}$ & $\begin{array}{l}\text { Ranks } \\
\text { awarded }\end{array}$ & $\begin{array}{l}\text { Mean } \\
\text { score }\end{array}$ \\
\hline 1. Primary care prescribing and the secondary sector & 5 & $\begin{array}{l}4,4,4,5 \\
5\end{array}$ & 4.4 \\
\hline $\begin{array}{l}\text { 2. Nurse prescribing: what are the benefits in the management of } \\
\text { venous leg ulcers? }\end{array}$ & 8 & $\begin{array}{l}2,2,3,4 \\
4,4,4,5\end{array}$ & 3.5 \\
\hline $\begin{array}{l}\text { 3. Information needs of women requesting Hormone Replacement } \\
\text { Therapy (HRT): how can this be best addressed? }\end{array}$ & 6 & $\begin{array}{l}3,3,3,3 \\
4,5\end{array}$ & 3.5 \\
\hline 4. GP repeat prescribing: the role of the community pharmacist. & 12 & $\begin{array}{l}1,1,2,2 \\
2,3,4,5 \\
5,5,5,5\end{array}$ & 3.3 \\
\hline 5. Generic prescribing: what are the hazards ? & 7 & $\begin{array}{l}1,1,3,3 \\
3,3,4,5\end{array}$ & 2.9 \\
\hline $\begin{array}{l}\text { 6. The older patient and effective medication: the role of the health } \\
\text { professional. }\end{array}$ & 4 & $1,2,2,2$ & 1.8 \\
\hline
\end{tabular}

Table 2 Responses to the two round Delphi Questionnair

\begin{tabular}{|c|c|c|}
\hline The participants & $\begin{array}{l}1 \text { st round } \\
\text { response } \\
\text { rate }\end{array}$ & $\begin{array}{l}\text { 2nd round } \\
\text { response } \\
\text { rate }\end{array}$ \\
\hline $\begin{array}{l}\text { Single handed GPs } \\
(n=15)\end{array}$ & $\begin{array}{l}60 \% \\
(n=9)\end{array}$ & $\begin{array}{l}47 \% \\
(n=7)\end{array}$ \\
\hline $\begin{array}{l}\text { GPs in a Group Practice } \\
(n=15)\end{array}$ & $\begin{array}{l}60 \% \\
(n=7)\end{array}$ & $\begin{array}{l}40 \% \\
(n=6)\end{array}$ \\
\hline $\begin{array}{l}\text { Practice nurses } \\
(n=15)\end{array}$ & $\begin{array}{l}47 \% \\
(n=7)\end{array}$ & $\begin{array}{l}20 \% \\
(n=3)\end{array}$ \\
\hline $\begin{array}{l}\text { District nurses } \\
(\mathrm{n}=15)\end{array}$ & $\begin{array}{l}40 \% \\
(n=6)\end{array}$ & $\begin{array}{l}40 \% \\
(n=6)\end{array}$ \\
\hline $\begin{array}{l}\text { Community pharmacists } \\
(\mathrm{n}=28)\end{array}$ & $\begin{array}{l}64 \% \\
(n=18)\end{array}$ & $\begin{array}{l}43 \% \\
(n=12)\end{array}$ \\
\hline Total $=88$ & $\begin{array}{l}53 \% \\
(n=47)\end{array}$ & $\begin{array}{l}38 \% \\
(n=34)\end{array}$ \\
\hline
\end{tabular}

and Smail, 1999). Developing research capacity in primary care is an NHS priority (Department of Health, 1999; 2000). In this priority setting exercise we hoped that by actively involving service providers from differing professional groups, the emergent key research areas would reflect this multidisciplinary perspective, be relevant to practice and foster the engagement and involvement of health care professionals in any research projects that followed. The following

discussion examines the extent to which the consensus methods and their findings captured the multidisciplinary perspective.

\section{The nominal group interview}

The aim of the NGT is to combine idea generation and problem solving in a single meeting (Scott and Deadrick, 1982) while promoting a democratic interview style by virtue of the structured format (Van de Ven and Delbecq, 1972). Balanced participation was facilitated in two ways. Firstly, by equal representation of each professional group and secondly, the structured format of the NGT abating individual group domination by, for example turn-taking to present ideas and private ranking. The NGT format facilitates participation and promotes group ownership of ideas generated (Jones and Hunter, 2000; Moore, 1987; Van de Ven and Delbecq, 1972). In order to establish a shared rationale for the responses to the research areas posed, an opportunity for discussion of ideas was introduced rather than simply seeking clarification as advocated in traditional NGT literature (Moore, 1987; Van de Ven and Delbecq, 1972). The opportunity to discuss the rationale for ideas also helped build the group cohesion, while facilitating the classification and combination of seemingly disparate ideas into the ranked summary, which was the final output of the meeting. 
Table 3 Delphi consultation mean scores

\begin{tabular}{|c|c|c|c|c|c|c|c|c|}
\hline \multirow[t]{2}{*}{ Priority Research questions } & \multicolumn{2}{|c|}{ GPs } & \multicolumn{2}{|c|}{ Nurses } & \multicolumn{2}{|c|}{ Pharmacists } & \multicolumn{2}{|c|}{ Overall } \\
\hline & $1 \mathrm{st}$ & 2nd & $1 \mathrm{st}$ & 2nd & $1 \mathrm{st}$ & 2nd & $1 \mathrm{st}$ & 2nd \\
\hline & \multicolumn{2}{|c|}{ rounds } & \multicolumn{2}{|c|}{ rounds } & \multicolumn{2}{|c|}{ rounds } & \multicolumn{2}{|c|}{ rounds } \\
\hline $\begin{array}{l}\text { 1. How can health care professionals help } \\
\text { improve older patient's capacity for } \\
\text { effective medication management? }\end{array}$ & 6.94 & 7.00 & 7.77 & 7.56 & 7.83 & 7.33 & 7.51 & 7.27 \\
\hline $\begin{array}{l}\text { 2. Can community pharmacists contribute to } \\
\text { assuring the quality, safety and cost } \\
\text { effectiveness of GP repeat prescribing? }\end{array}$ & 5.69 & 6.08 & 7.54 & 7.67 & 8.47 & 7.36 & 7.24 & 6.97 \\
\hline $\begin{array}{l}\text { 3. What benefits might be associated with } \\
\text { nurse prescribing in the management of } \\
\text { venous leg ulcers? }\end{array}$ & 7.19 & 6.92 & 6.85 & 6.63 & 6.61 & 6.64 & 6.87 & 6.74 \\
\hline $\begin{array}{l}\text { 4. What hazards might be associated with } \\
\text { generic prescribing? }\end{array}$ & 6.94 & 6.00 & 7.38 & 5.50 & 5.00 & 5.82 & 6.32 & 5.81 \\
\hline $\begin{array}{l}\text { 5. To what extent is prescribing in primary } \\
\text { care secondary care led? }\end{array}$ & 5.44 & 4.92 & 4.82 & 6.00 & 5.06 & 5.67 & 5.13 & 5.47 \\
\hline $\begin{array}{l}\text { 6. How can the information needs of women } \\
\text { requesting HRT best be addressed? }\end{array}$ & 5.19 & 4.25 & 6.62 & 5.25 & 5.88 & 4.45 & 5.85 & 4.58 \\
\hline
\end{tabular}

\section{The Delphi process}

The Delphi technique enables consultation with geographically separated individuals. Since respondents do not meet as a group there is no peer pressure to reply in a particular way (Duffield, 1989). Individuals can take time to consider the questions posed and can use all available information to arrive at the answer (Goodman, 1987; Jones and Hunter, 2000). However, nonresponse and differential responses between professional groups can threaten the approach as a vehicle for eliciting multidisciplinary perspectives. The iterative nature of the Delphi process means that consensus, if it is achieved, occurs because the views of the participants converge through a process of informed decision making. Lack of consensus can also be significant, especially in an exercise seeking multidisciplinary perspectives (Goodman, 1987; Mckenna, 1994).

A stratified sampling technique ensured that different health professionals were represented in the Delphi process. However, response rates were lower for certain groups; for example, only 40 percent of district nurses responded while, for example, 60 percent of single handed GPs responded. Nevertheless, it was possible to look at the level of agreement between professional groups as well as the overall rankings, which ultimately guided the interpretation of the results of the consultation exercise.

\section{Outcomes}

The six questions generated from the NGT interview covered a wide range of research areas around the broad issue of prescribing and reflected the diversity of the professionals involved. The multidisciplinary composition of the group was productive with potential problems of status and uni-professional domination abated through the structured format. It is unlikely that a uniprofessional homogenous group would have generated the same diversity of responses to the original research question (Murphy et al., 1998).

The first and second highest ranked questions (see Table 3) in the Delphi focused on quality and effectiveness issues and featured, or implied, partnerships between professional groups as an important feature of likely problem solutions. This assertion is supported by the consistently high priority they were awarded, across the three professional groups, during both rounds. 
The area of nurse prescribing and leg ulcer management (question 3) converged as a priority research area in both stages of the consultation exercise and across professional groupings. The question assumes a change in the way that care may be organized in response to the implementation of nurse prescribing (Crown, 1989). General practitioners and nurses were keen to consider the impact of these changes on the cost and quality of leg ulcer management. Pharmacists also appeared to recognize its importance and their contribution and role in this research area. The weighting this question was awarded by all three disciplines demonstrates how diversity in a decision making team facilitates the incorporation of ideas beyond an individual's own professional arena.

Two of the three lowest ranking questions were less patient oriented, centring on issues of generic prescribing and the secondary/primary care sector interface. Interactions between the professional groups did not feature strongly.

\section{Study limitations}

The consensus methods used were not without limitations. The NGT interview participants might be unrepresentative of their professional group, although their self-selection may have enhanced the depth of the research enquiry. To prevent individual group size bias district nursing and practice nursing were amalgamated under the heading 'primary care nurses'. The differences between these specialities (e.g., mode of employment and practice population) might lead them to differing research priorities.

The Delphi process is vulnerable to differential response rates and attrition between sequential rounds. The low response rate by some of the professional groups, although not untypical (Frankfort-Nachmias and Nachmias, 1996), would make reliance on the findings problematic if the responders are unrepresentative of the wider population (Cartwright, 1978). Use of central measures of location goes some way towards preventing group size bias in the interpretation of the Delphi respondents' judgements, but does not exclude it.

\section{Conclusion}

The aim of this paper was to report on the feasibility of using consensus methods to establish multidisciplinary perspectives on research priorities in primary care. The NGT was found to be an effective approach for generating and ranking questions whilst accommodating different professional views. The Delphi process established the view of a wider constituency. The methods have limitations, but the final research questions generated reflected the multidisciplinary nature of the study and priority issues for practice. Moreover, the consultation methods provided a means for practitioners to participate in the research process and might secure the interest of relevant professional groups for future research endeavours.

\section{Acknowledgements}

We would like to thank Tracey Chandler for her invaluable organizational and secretarial support; Roger Davies and Dr Catherine Duggan for contributing to the study design and execution; Cheryl Davies, Sharon Steele, Jenny Ayres, Suhas Khandaria, Sally Shulman and Elaine Ward for collaborating in the study design.

\section{References}

Carney, O., McIntosh, J. and Worth, A. 1996: The use of the nominal group technique in research with community nurses. Journal of Advanced Nursing 23(4), 1024-29.

Cartwright, A. 1978: Professionals as responders: variations in and effects of response rates to questionnaires, 1961-77. British Medical Journal 2(6149), 1419-21.

Crown, J. 1989: Report of the Advisory Group on Nurse Prescribing (Crown Report). London: Department of Health.

Department of Health. 2000: The NHS Plan; a plan for investment a plan for reform. London: Department of Health.

Department of Health. 1999: Making a Difference: strengthening the nursing, midwifery and health visiting contribution to health and health care. London: Department of Health.

Department of Health. 1997a: The New NHS. Modern and Dependable. London: HMSO.

Department of Health. 1997b: Research and Development in Primary Care. National Working Group Report. London: HMSO.

Duffield, C. 1989: The Delphi technique. Australian Journal of Advanced Nursing 6(2), 41-45. 
Elwyn, G. and Smail, J. 1999: Integrated teams in primary care. Radcliffe: Abingdon.

Frankfort-Nachmias, C. and Nachmias, D. 1996: Research Methods in the Social Sciences (5th edin). London: Arnold.

Goodman, C. 1987: The Delphi technique: a critique. Journal of Advanced Nursing 12, 729-34.

Hares, T., Spencer, J., Gallagher, M., Bradshaw, C. and Webb, I. 1992: Diabetes care: who are the experts? Quality Health Care 1, 219-24.

Jones, J. and Hunter, D. 2000: Using the Delphi and nominal group techniques in health services research. In Pope, C. and Mays, N., editors, Qualitative Research in Health Care. London: British Medical Journal, 40-49.

Mckenna, H. 1994: The Delphi technique: a worthwhile research approach for nursing? Journal of Advanced Nursing 19, 1221-25.

Moore, J. 1987: Group Techniques for Idea Building. Newbury Park: Sage.

Murphy, M.K., Black, N.A., Lamping, D.L., Mckee, C.M.,
Sanderson, G.F.B., Askham, J. and Marteau, T. 1998: Consensus development methods, and their use in clinical guideline development. Health Technology Assessment 2(3), 1-88.

Poxton, R. editors. 1999: Working across the boundaries: experiences of primary health and social care partnerships in practice. London: Kings Fund.

Scott, D. and Deadrick, D. 1982: The nominal group technique: applications for training needs assessment. Training and Development Journal 7, 26-33.

Van de Ven, A.H. and Delbecq, A.L. 1972: The nominal group as a research instrument for exploratory health studies. Journal of the American Medical Association 62(3), $337-42$.

Whitford, D., Jelley, D.I., Gandy, S., Southern, A. and Van Zwanenberg, T. 2000: Making Research relevant to the primary health care team. British Journal of General Practice $50,573-76$. 